\title{
Obtention de plantes indemnes du virus de la mosaïque de l'igname (YMV) par culture in vitro des apex chez l'igname américaine Dioscorea trifida $L$
}

\author{
V Saleil 1, L Degras 2, R Jonard 1 \\ avec la collaboration technique de P Hamard, P Quétin et P Bal \\ ${ }^{1}$ Université des Sciences et Techniques du Languedoc, laboratoire d'histophysiologie végétale, 34060 Montpellier Cedex \\ ${ }^{2}$ Centre INRA-Antilles-Guyanne, station d'amélioration des plantes, BP 1232 Pointe-à-Pitre Cedex, France
}

(Reçu le 8 février 1990; accepté le 7 juillet 1990)

\begin{abstract}
Résumé - Chez les ignames, une maladie à virus (Yam mosaic virus, YMV) affecte gravement la culture et réduit les échanges de ressources génétiques. La régénération de plantes sans virus a été recherchée, chez Dioscorea trifida L, par culture d'apex de vitroplants issus de boutures nodales de matériel contaminé. Le développement in vitro a été réalisé en 3 phases :

- dépôt et reprise du fonctionnement de l'apex sur solution minérale N $30 \mathrm{~K}$ de Margara, comportant une cytokinine (BAP à $8,88 \mu \mathrm{mol} / \mathrm{l}$ ) et une auxine (AIB à $0,049 \mu \mathrm{mol} / \mathrm{l})$

- allongement et multiplication des pousses feuillées sont favorisés par un passage sur une solution minérale de Murashige et Skoog avec macroéléments dilués de moitié (MS/2) avec BAP $(0,88 \mu \mathrm{mol} / \mathrm{l})$ et AIB $(0,049 \mu \mathrm{mol} / \mathrm{l})$

- enracinement des vitroplants de longueur suffisante. II est induit par trempage dans une solution de saccharose (80 g. $\left.\mathrm{I}^{-1}\right)$ et ANA $(2,67 \mu \mathrm{mol} / \mathrm{l})$.

Les vitroplants sont transférés directement en substrat horticole. L'utilisation du test immunoenzymatique ELISA indique que $27 \%$ des plantes issues de culture d'apex in vitro sont ainsi débarrassées du YMV.
\end{abstract}

morphogenèse / organogenèse / phytohormone / technique ELISA

Summary - Cleaning the Dioscorea trifida L yam from yam mosaic virus (YMV) through apices in vitro culture. The Dioscorea trifida $L$ yam is particularly susceptible to the yam mosaic virus (YMV) which severely affects most yam cultures and reduces the exchange of genetic resources. Healthy plants have been sought through apical meristem tip in vitro culture of vitroplantlets obtained from nodal explants of diseased material.

This was performed in 3 phases:

1) Outgrowth or organisation of the apex over a paper bridge (fig 1) on a mineral solution of Margara ("N $30 \mathrm{~K}$ ), including a cytokinin (BAP $8.88 \mu \mathrm{mol} / \mathrm{l}$, fig 2) an auxin (IBA $0.049 \mu \mathrm{mol} / \mathrm{l}$ ) and gibberellin (GA $2.9 \mu \mathrm{mol} / \mathrm{l}) ; 2$ ) Lengthening and multiplication of leafed buds (fig 3 ) benefited from one subculture on a mineral solution of Murashige and Skoog with half diluted macro elements (MS/2, table II) BAP (0.88 $\mu \mathrm{mol} /$, table III) and IBA (0.049 $\mu \mathrm{mol} / \mathrm{l}$ and gibberellin (0.29 $\mu \mathrm{mol} / \mathrm{l})$; 3) Shoots which had grown enough were rooted (fig 4) by dipping in a solution of sucrose (80 g/l) and ANA (2.67. $\mu \mathrm{mol} / \mathrm{l}$, fig 5).

The vitroplantlets were directly transferred in horticultural substrate. Those not cleaned could not then express their virus symptoms (fig 6). The application of the immuno enzymatic test Elisa established that $27 \%$ of the plants grown from in vitro apex culture are free from YMV (fig 7).

morphogenesis / organogenesis / phytohormone / Elisa test 


\section{INTRODUCTION}

Les ignames (Dioscorea spp), monocotylédones rattachées aux Liliales, regroupent environ 600 espèces, essentiellement intertropicales (Coursey, 1967). L'utilisation alimentaire du genre remonte aux temps préhistoriques et les espèces cultivées actuellement contribuent à nourrir des dizaines de millions d'hommes. Aujourd'hui, dans les régions tropicales humides, leur production serait la seconde après celle du manioc. Quelques espèces, riches en stéroïdes, demeurent, après avoir dominé le marché de la diosgénine, des sources importantes d'hormones sexuelles contraceptives et de corticoïdes (Degras, 1986).

Les Dioscorea cultivées, dont la reproduction sexuée est aléatoire, sont multipliées essentiellement par voie végétative, ce qui entraîne la dissémination d'agents pathogènes dans les plantations, provoquant une baisse de rendement et de qualité des récoltes (Degras, 1986). Contre les champignons parasites du tubercule la combinaison de tri à la récolte, de conditions de conservation adaptées et de trempage dans des fongicides est efficace. Contre les nématodes, si la charge n'est pas excessive, la thermothérapie humide ou des nématicides peuvent agir utilement. Mais la thermothérapie du tubercule s'étant montrée inopérante contre les viroses (Mantell et al, 1977) la culture in vitro paraissait la seule voie pour obtenir les plants sains nécessaires à la production, et à l'échange des ressources génétiques, chez l'igname.

La culture in vitro d'ignames, amorcée par des études méthodologiques de recherche physiologique chez $D$ opposita Thumb (Sawada et al, 1958), D composita Hemsl (Nickell in Gautheret, 1959), $D$ bulbifera L (Uduebo, 1971), devait ensuite accroître la propagation des ignames à diosgenine (Chaturvedi, 1975, Grewal et al, 1977), puis des ignames alimentaires (Mantell et al, 1978, Arnolin, 1980). En 1979, Mantell et Haque présentaient (voir aussi Mantell et al, 1980) une technique, thermothérapie de la plante mère suivie de culture d'apex in vitro, pour éliminer le complexe viral tenu pour responsable de désordres tissulaires dans les tubercules de certaines $D$ alata L. A l'IITA (Nigéria), en 1988, NG signale la disponibilité de 300 clones d'igname débarrassés de virus par une technique analogue.

En simplifiant quelque peu (voir Degras, 1986, pour les données acquises à l'époque) nous rap- pellerons que les travaux de Adsuar (1955), Harrison et Roberts (1973), Migliori et Cadilhac (1976), Mohamed et Mantell (1976), Mantell et al, (1977), Terry (1978), Thouvenel et Fauquet (1977, 1979, 1980 a, 1980 b, 1986), Marchoux et al, (1979), Balagne (1985), Fauquet et Thouvenel (1987) permettent de concevoir l'existence d'un complexe viral chez les principales ignames alimentaires, auquel participeraient notamment un potyvirus de $700-800 \mathrm{~nm}$, un virus bacilliforme et la mosaïque du concombre (CMV) ou un virus à particule isométrique. Thouvenel et Fauquet ont décrit en 1986 ce potyvirus, le plus commun, sous le nom de Yam Mosaic Virus (YMV), et en ont obtenu un antisérum en Côte-d'Ivoire. L'utilisation de celui-ci par le test Elisa, mis au point par Clark et Adams (1977), a permis d'établir une étroite parenté entre les pathotypes isolés en Côte-d'Ivoire et ceux de la Guadeloupe (Marchoux et al, 1979), du Togo (Reckhaus et Nienhaus, 1981) et du Nigéria (Thottapilly, communication personnelle).

De toutes les Dioscorea cultivées aux Antilles, $D$ trifida $L$ apparaissait comme la plus affectée dans sa croissance et son rendement par les viroses (Migliori et Cadilhac, 1976, Marchoux, 1980). Seule igname alimentaire fructifiant abondamment dans cette aire, elle avait pu bénéficier, dès 1966, d'un programme d'amélioration génétique (Degras, 1978, Degras et al, 1980) qui se heurtait bientôt à l'absence de géniteurs de résistance aux viroses. On chercha ces derniers à partir de leur aire d'origine présumée et deux méthodologies de régénération des clones furent mises en œuvre. Au laboratoire des plantes vivrières de la station d'amélioration des plantes (INRA), en Guadeloupe, avec le concours de la station de pathologie végétale notamment, la thermothérapie in vitro suivie de micropropagation devait se montrer efficace (Balagne, 1985). Au laboratoire de physiologie végétale appliquée de I'USTL, la culture d'apex de $D$ trifida, sans thermothérapie, fut la base de la recherche ici présentée.

\section{MATÉRIEL ET MÉTHODES}

Des explants issus de plantes virosées contrôlées par test Elisa, ont été cultivés in vitro, d'abord à partir de régions nodales puis d'apex des vitroplants obtenus. Les vitroplants issus d'apex ont été transférés en substrat horticole et leur décontamination virale a été évaluée par le test Elisa. 


\section{Cultivar}

II s'agit du clone $D$ trifida «INRA 5-20", hybride issu de la sélection INRA en Guadeloupe. II se caractérise par une bonne qualité culinaire de ses tubercules sphéroïdes, une potentialité de rendement élevée mais est particulièrement sensible aux viroses (Degras et al, 1980).

\section{Culture in vitro}

\section{Par explant nodal}

Introduit par l'un de nous (Degras, 1983) de la Guadeloupe à Montpellier, sous forme de vitroplants, ce matériel a été maintenu par micropropagation nodale au laboratoire de culture des tissus du CIRAD avec des cycles de repiquage de 2 à 5 mois, en général sur le milieu N $30 \mathrm{~K}$ de Margara (1978). Les repiquages effectués au laboratoire de l'université ont été faits par la suite avec $50 \mathrm{~g} . \mathrm{I}^{-1}$ de saccharose au lieu de $30 \mathrm{~g} . \mathrm{I}^{-1}$ de la technique initiale.

\section{Par explant apical}

Des essais préliminaires nous ont conduits à prélever sur les vitroplants des apex de 0,2-0,5 mm de diamètre comprenant le dôme méristématique accompagné ou non d'une ébauche foliaire. Ils sont ensuite placés dans des tubes à hémolyse sur un pont de papier filtre dont les extrémités plongent dans une solution nutritive liquide. Nous avons utilisé 2 types de combinaisons de macro-éléments : le milieu de Margara (1978), N $30 \mathrm{~K}$, et le milieu de Murashige et Skoog (1962), mais celui-ci dilué de moitié (MS/2) ou du quart (MS/4) pour $\mathrm{NH}_{4} \mathrm{NO}_{3}$ et $\mathrm{KNO}_{3}$. A ces macro-éléments étaient ajoutés les micro-éléments de Murashige et Skoog, et, éventuellement des vitamines (mésoinositol, $555 \mu \mathrm{mol} / /$, biotine à $0,04 \mu \mathrm{mol} / \mathrm{l}$ ), du fer chélaté avec $100 \mu \mathrm{mol} / \mathrm{l}$ de $\mathrm{FeSO}_{4}, 7 \mathrm{H}_{2} \mathrm{O}$ et $100 \mu \mathrm{mol} / \mathrm{l}$ de $\mathrm{Na}_{2}$ EDTA, et du saccharose $\left(30 \mathrm{~g} . \mathrm{I}^{-1}\right)$. Diverses substances de croissance compléteront ces milieux de base, leur nature sera précisée ultérieurement. Le pH des solutions est ajusté à $5,6 \pm 0,1$ avec $\mathrm{KOH}$ ou $\mathrm{HCl}$ avant leur stérilisation à l'autoclave à $110^{\circ} \mathrm{C}$ pendant $20 \mathrm{~min}$.

Les explants sont placés à $25^{\circ} \mathrm{C} \pm 2{ }^{\circ} \mathrm{C}$, sous un éclairement de $37 \mu$ Einstein. $\mathrm{m}^{-2} \mathrm{~s}^{-1}$ environ pendant $16 \mathrm{~h}$ par jour.

\section{Transfert en serre}

Les plantules enracinées sont acclimatées en serre à $27{ }^{\circ} \mathrm{C}$ sur un mélange (parts égales) terreauvermiculite préalablement stérilisé par un double autoclavage à $120^{\circ} \mathrm{C}$ pendant $1 \mathrm{~h}$.

\section{Détection du virus de la mosaïque de l'igname (YMV)}

La technique de Clark et Adams (1977) du test sérologique Elisa préconisée par Thouvenel et Fauquet $(1980 \mathrm{a}, \mathrm{b})$ a été mise en œuvre, avec le concours de JB Quiot, au laboratoire de phytovirologie des pays chauds (CIRAD-Montpellier) et avec l'antisérum fourni par JC Thouvenel (ORSTOM, Côte-d'lvoire). Les tests ont été effectués avec une concentration en globuline de revêtement de $10 \mu \mathrm{g} \cdot \mathrm{ml}^{-1}$, un conjugué dilué au $1 / 1000$ pour un rapport optimal virosé/sain estimé par densité optique de 29, à $405 \mathrm{~nm}$. Les échantillons étaient dilués au 1/50. L'échantillon virosé provenait de 3 plantes à symptômes foliaires graves. Faute de graines de $D$ trifida, rares du tait des viroses, l'échantillon sain était constitué de plantules, âgées de 3 semaines, issues de graines de $D$ cayenensisrotundata*, car la virose n'est pas transmise par la graine (Marchoux et al, 1979).

\section{RÉSULTATS}

Nous considérons d'abord les milieux successifs en référence aux phases de dépôt et reprise de fonctionnement des apex, d'accélération de l'allongement avec multiplication des tiges, et de rhizogenèse, avant d'évoquer le transfert en serre et le contrôle sanitaire.

\section{Phase de dépôt et reprise de fonctionnement des apex (fig 1)}

II s'agit d'une période de l'ordre de $20-30$ j pendant laquelle les apex mettent en place les nouvelles ébauches foliaires et entrent lentement en croissance. Celle-ci demeure de l'ordre de $0,10 \mathrm{~mm} / \mathrm{j}$ avant de s'accélérer.

En ce qui concerne les équilibres minéraux, on remarque que le milieu $\mathrm{N} 30 \mathrm{~K}$ conduit à un allongement à peu près double de celui induit par tous les autres, y compris le $M S / 2$, qui a la même teneur en azote mais avec un rapport $\mathrm{NO}_{3} / \mathrm{NH}_{4} 2$ fois plus faible.

La nature et la dose de la cytokinine déterminent des variations de croissance significa-

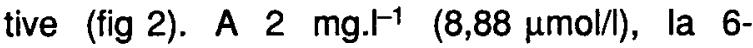
benzyl-aminopurine (BAP) permet de dépasser $0,10 \mathrm{~mm} / \mathrm{j}$.

Trois auxines ont été expérimentées. L'acide napthalène acétique (ANA) aux doses utilisées ne provoque guère de variation et n'assure pas un taux élevé de reprise. L'acide $B$ indolylacétique (AIA) et l'acide B indolylbutyrique (AIB),

\footnotetext{
- Ce complexe spécifique recouvre les taxons $D$ cayenencis Lam et $D$ rotundata Poir.
} 


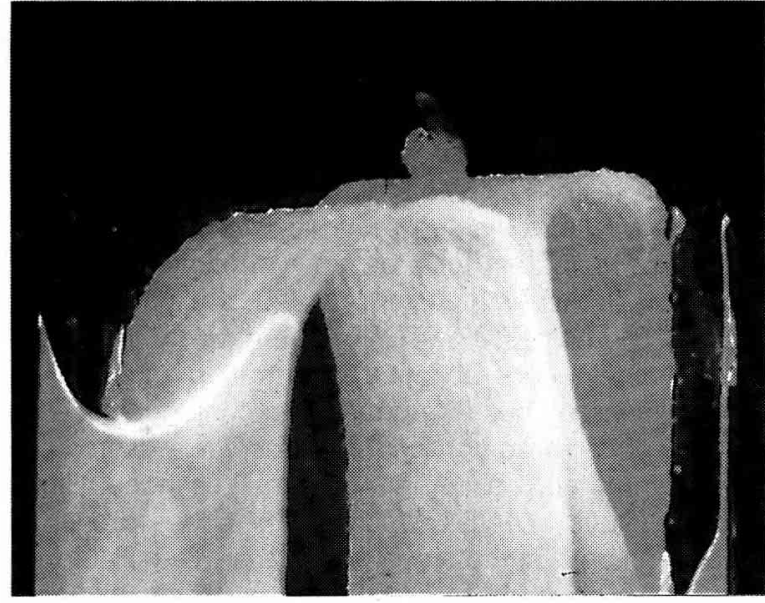

Fig 1. Début de croissance d'un explant apical de $D$ trifida sur pont de papier filtre et milieu liquide.

induisent, à certaines doses, plus de $90 \%$ de reprise. L'AIB à la dose de $0,01 \mathrm{mg}^{-1}(0,049$ $\mu \mathrm{mol} / \mathrm{l})$ provoque un débourrement avec une fréquence élevée et un allongement maximal (tableau I). Des cals défavorables à la croissance ont été observés avec toutes les auxines à la dose de $1 \mathrm{mg} \cdot \mathrm{l}^{-1}$.

L'acide gibberellique n'a d'action qu'en présence de cytokinine et d'auxine (en combinaison optimale); il accroît l'allongement jusqu'à $0,15 \mathrm{~mm} / \mathrm{j}$, avec $1 \mathrm{mg} . \mathrm{I}^{-1}(2,9 \mu \mathrm{mol} / \mathrm{l})$ contre $0,05 \mathrm{~mm}$ pour le témoin.

\section{Phase d'allongement accéléré et de ramifica- tion (fig 3)}

Au cours de cette phase, la croissance axiale est de l'ordre de 0,4 mm/j.

Les apex ayant repris sont transférés, vers le $40^{\circ} \mathrm{j}$ de culture, sur un nouveau milieu favorisant leur développement en jeunes pousses feuillées.
Le milieu MS dilué à $50 \%$ ou à $25 \%$ fournit des résultats supérieurs à ceux du $\mathrm{N} 30 \mathrm{~K}$ (tableau II). La réduction du rapport $\mathrm{NO}_{3} / \mathrm{NH}_{4}$ paraît ainsi avantageuse étant donné le nombre de plants en prolifération, leur taux de multiplication, et certains dysfonctionnements tissulaires («vitrifi-cation»).

Contrairement à ce qui se passe dans la phase précédente, la dose de BAP la plus efficace est la plus faible essayée, mais la présence de la BAP demeure nécessaire (tableau III). Par contre, comme pour la phase de reprise, la teneur optimale en AIB paraît être de $0,049 \mu \mathrm{mol} / \mathrm{l}$.

\section{Phase d'enracinement (fig 4)}

Les pousses de 60-70 j sont d'abord trempées pendant 7-10 j dans un milieu liquide induisant la rhizogenèse. II renferme la solution minérale MS/ 4 , suivant en cela une technique appliquée par Sengupta et al, (1984) à $D$ floribunda Mart et Gal. L'ANA seulement, comparé à l'AIB et I'AIA, s'est montré utile; il a une activité synergique avec celle du saccharose quand celui-ci passe de 30 à $80 \mathrm{~g} .1^{-1}$, l'ANA passant de 0 à $0,5 \mathrm{mg} . \mathrm{l}^{-1}$ $(2,67 \mu \mathrm{mol} / /)$. L'interaction devient négative avec $1 \mathrm{mg} . \mathrm{l}^{-1}(5,34 \mu \mathrm{mol} / \mathrm{l})$ d'ANA (fig 5).

Au bout de 7-10 j, les pousses sont repiquées sur un milieu gélosé à $7 \mathrm{~g} . \mathrm{I}^{-1}$ et contenant, avec $30 \mathrm{~g} . \mathrm{l}^{-1}$ de saccharose, les éléments minéraux du N $30 \mathrm{~K}$.

\section{Passage aux conditions naturelles}

Avec la procédure indiquée pour le transfert en serre, le taux de reprise a été de $100 \%$. Les feuilles nouvellement développées retrouvent

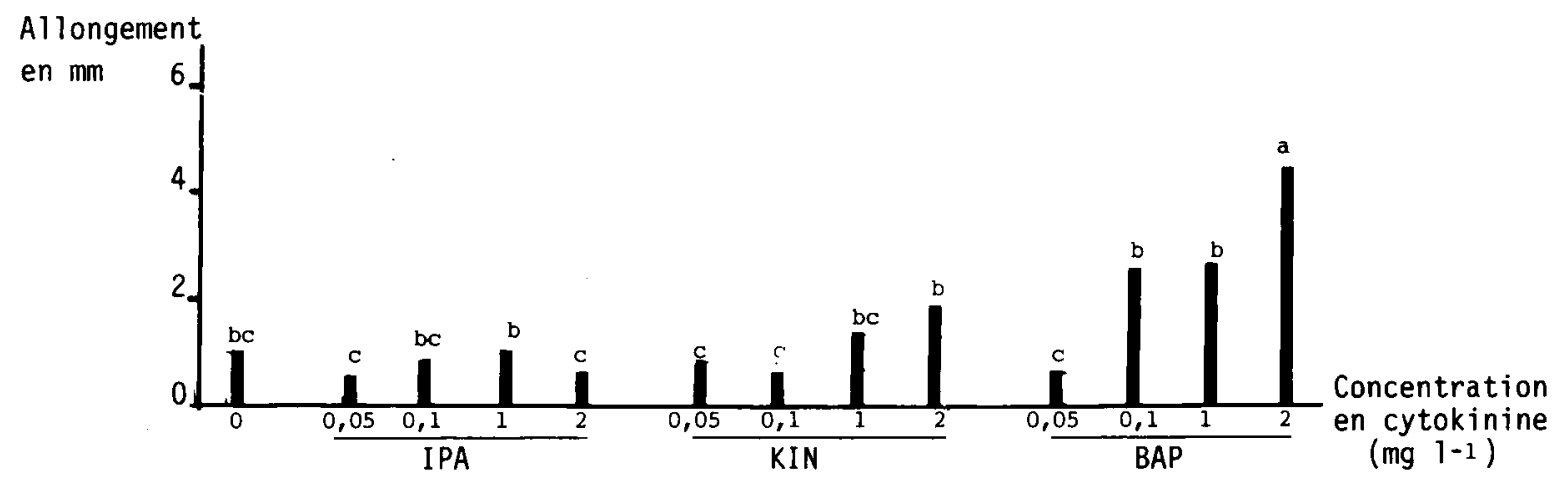

Fig 2. Influence de diverses cytokinines sur l'allongement des apex de $D$ trifida cv INRA 5-20, 30 j après leur mise en culture. Le milieu de base contient GA3 $\left(1 \mathrm{mg} \cdot \mathrm{I}^{-1}=2,9 \mu \mathrm{mol} / \mathrm{h}\right)$ et AIB $\left(0,01 \mathrm{mg} \cdot \mathrm{l}^{-1}=0,049 \mu \mathrm{mol} / \mathrm{l}\right)$. II y a 48 explants pour chaque condition expérimentale. Les lettres au-dessus des colonnes indiquent les groupements statistiques IPA : Isopentenyl ( $\mu \mathrm{mol} / 1: x 4,93) ; \mathrm{KIN}: \mathrm{Kine}-$ tine $(\mu \mathrm{mol} / \Omega$ : $x 4,65)$; BAP : 6-benzyl-aminopurine $(\mu \mathrm{mol} /$ : $\times 4,44)$. 


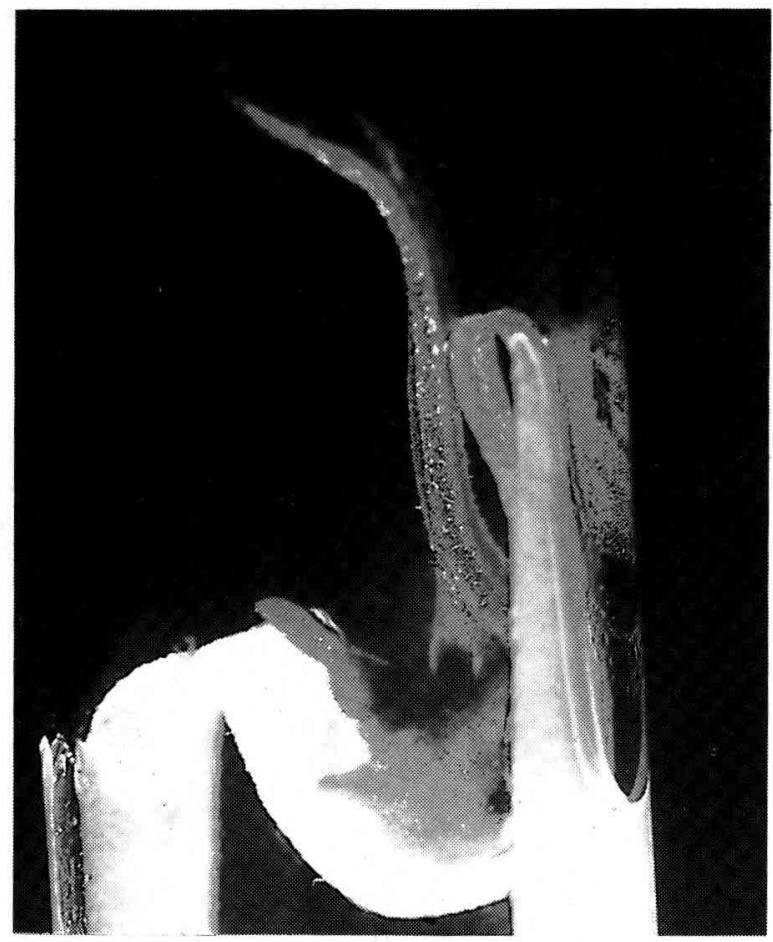

Fig 3. Bourgeonnement et prolifération de la pousse de $D$ trifida après transfert sur un nouveau milieu.

d'emblée la morphologie lobée de la plante d'origine, disparue en culture in vitro (Arnolin, 1985, Arnolin et Degras, 1983).

\section{La détection du virus de la mosaïque de l'igname}

Après leur sortie des tubes, les plantes poursuivent leur développement et sont suivies pendant 6 mois. On peut ainsi noter l'apparition éventuelle et l'évolution des différents symptômes foliaires de viroses : mosaïque accompagnée de nervures

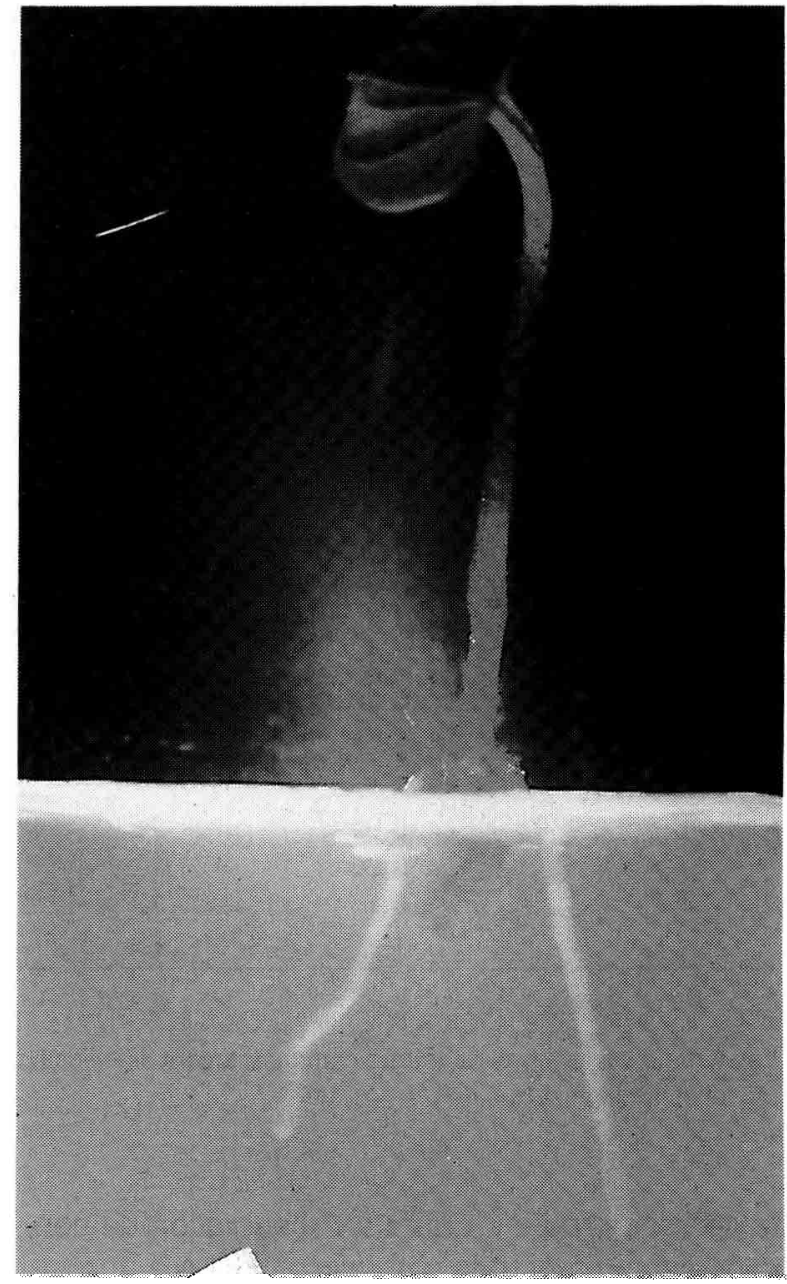

Fig 4. Enracinement de la vitroplantule de $D$ trifida sur milieu solide in vitro.

bordées de vert plus sombre, altération légère de la coloration du limbe parfois associée à une mosaïque (fig 6). Ces symptômes sont difficilement reconnaissables lorsque les plantes sont conservées en tube. II convient cependant de

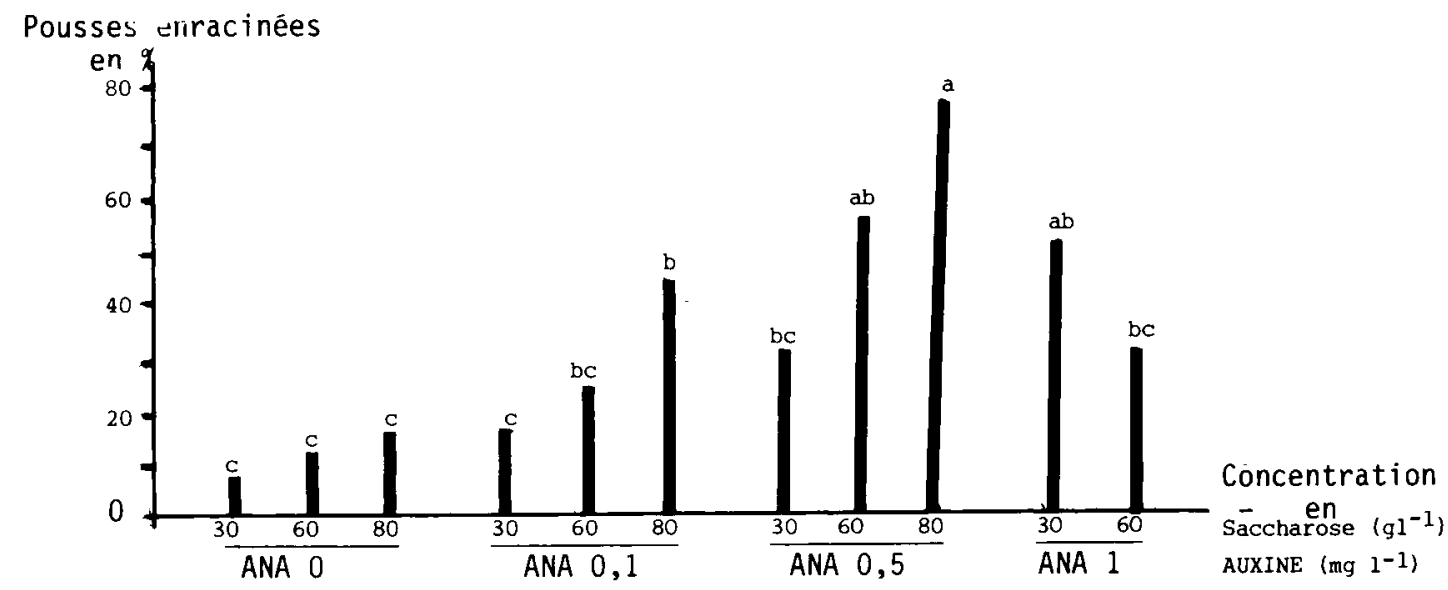

Fig 5. Enracinement in vitro des pousses de $D$ trifida cv INRA 5-20 en fonction des concentrations en ANA et saccharose des solutions de trempage, 48 pousses sont utilisées pour chaque condition. Les lettres sur les colonnes indiquent les groupements statistiques. 
Tableau I. Effets de 3 auxines à différentes concentrations sur le développement d'apex de $D$ trifida en présence de BAP à $2 \mathrm{mg}^{-1}(8,8 \mu \mathrm{mol} / \mathrm{l})$ et de $\mathrm{GA}_{3}$ à $1 \mathrm{mg} \mathrm{l}^{-1}(2,9 \mu \mathrm{mol} / \mathrm{l})$.

\begin{tabular}{|c|c|c|c|c|c|}
\hline $\begin{array}{l}\text { Traitement } \\
\left(m g \cdot{ }^{-1}\right)\end{array}$ & & $\begin{array}{l}\text { Nombre d'apex } \\
\text { mis en culture }\end{array}$ & $\begin{array}{c}\text { Nombre d'apex } \\
\text { débourrés, } \\
20 \text { j après l'excision }\end{array}$ & $\begin{array}{c}\% \text { de } \\
\text { débourrement }\end{array}$ & $\begin{array}{c}\text { Allongement des } \\
\text { pousses }(\mathrm{mm}) \\
\text { à } 60 j\end{array}$ \\
\hline \multirow[t]{2}{*}{ Témoin } & & 20 & 10 & $50^{b}$ & 5,6 \\
\hline & 0,01 & 21 & 19 & $90,5^{a}$ & 9,2 \\
\hline \multirow[t]{4}{*}{ AIB } & 0,05 & 24 & 20 & $83,3^{a b}$ & - \\
\hline & 0,1 & 24 & 22 & $91,7^{a}$ & 8,8 \\
\hline & 1 & 21 & 14 & $66,7 a b$ & 6,2 \\
\hline & 0,01 & 24 & 22 & $91,7^{a}$ & \\
\hline \multirow[t]{4}{*}{ AIA } & 0,05 & 19 & 11 & $57,9^{a b}$ & \\
\hline & 0,1 & 10 & 11 & $57,9 a b$ & \\
\hline & 1 & 19 & 8 & $42,1^{b}$ & \\
\hline & 0,01 & 21 & 14 & $66,7^{\mathrm{ab}}$ & \\
\hline \multirow[t]{3}{*}{ ANA } & 0,05 & 22 & 14 & $63,6 \mathrm{ab}$ & \\
\hline & 0,1 & 23 & 15 & $65,2^{a b}$ & \\
\hline & 1 & 22 & 14 & $63,6^{a b}$ & \\
\hline
\end{tabular}

Les lots ne portant pas de lettres communes sont significativement différents au seuil de $5 \%$ (test du $\chi^{2}$ ). Le milieu témoin est celui qui n'est additionné que de $\mathrm{GA}_{3}$ et BAP.

rester très prudent quant à l'observation de certains symptômes pouvant laisser croire à une atteinte pathologique alors qu'il ne s'agit, en réalité, que de manifestations dues à des déficiences nutritives (Thouvenel et Fauquet, 1980 a). De plus, il n'est pas rare d'observer des feuilles d'apparence virosée succédant à des feuilles apparemment saines, ce qui a déjà été noté par Marchoux (1980).

Pour ces raisons, au cours des 6 mois de suivi en serre, le test Elisa a été appliqué, en fé- vrier et en avril, sous la direction de JB Quiot. La première série de tests à porté sur 26 plants, la seconde sur 22 plantes, dont 15 avaient subi un test en février. La figure 7 montre une bonne répétitivité des résultats d'un test à l'autre : en effet, les plantes présentant une faible DO au mois de février conservent au mois d'avril une absorbance proche de celle du témoin sain. II convient de distinguer :

- les plantes Nos $29,7,32,33,24,22,25,30$ et 27 de DO très proche de celle du témoin sain dans les 2 séries de tests;

Tableau II. Multiplication des pousses de $D$ trifida en présence de différentes solutions minérales.

\begin{tabular}{lcccc}
\hline Traitements & $\begin{array}{c}\text { Fréquence des explants primaires } \\
\text { portant plusieurs pousses (\%) }\end{array}$ & $\begin{array}{r}\text { Nombre de bourgeons néoformés } \\
\text { sur les explants à pousses multiples }\end{array}$ & $\begin{array}{c}\text { Taux de } \\
\text { multiplication }\end{array}$ \\
\hline MS & $20 / 48$ & $41,7^{\mathrm{b}}$ & $42 / 20$ & 2,1 \\
MS/2 & $41 / 47$ & $87,2^{\mathrm{a}}$ & $240 / 41$ & 5,8 \\
MS/4 & $41 / 48$ & $85,4^{\mathrm{a}}$ & $223 / 41$ & 5,4 \\
N3OK & $28 / 45$ & $62,2^{\mathrm{ab}}$ & $120 / 28$ & 4,3 \\
N15K & $26 / 46$ & 56,5 & $54 / 26$ & 2,1 \\
\hline
\end{tabular}


Tableau III. Action de la BAP sur le développement de jeunes pousses de $D$ trifida après $60 \mathrm{j}$ de culture.

\begin{tabular}{|c|c|c|c|c|c|}
\hline $\begin{array}{l}\text { Traitement } \\
\left(m g \cdot{ }^{-1}\right) \\
(\mu m o / \cdot /-1)\end{array}$ & $\begin{array}{c}\text { Fréquences des explants } \\
\text { primaires portant } \\
\text { plusieurs pousses }\end{array}$ & $\%$ & $\begin{array}{l}\text { Nombre de bourgeons } \\
\text { néoformés sur les explants. } \\
\text { à pousses multiples }\end{array}$ & $\begin{array}{c}\text { Taux de } \\
\text { multiplication }\end{array}$ & Observations \\
\hline BAP 0 & $28 / 47$ & 59,6 & $58 / 28$ & 2,1 & $\begin{array}{l}\text { peu d'allongement } \\
\text { croissance réduite }\end{array}$ \\
\hline BAP $0,2(0,89)$ & $40 / 48$ & 83,3 & $195 / 40$ & 4,9 & allongement optimal \\
\hline BAP $0,5 \quad(2,22)$ & $31 / 46$ & 67,4 & $135 / 31$ & 4,3 & allongement réduit \\
\hline BAP $1 \quad(4,44)$ & $15 / 40$ & 37,5 & $29 / 15$ & 1,9 & allongement faible \\
\hline BAP $2 \quad(8,88)$ & $6 / 28$ & 21,4 & $12 / 6$ & 2 & $\begin{array}{l}\text { mortalité importante } \\
\text { des explants }\end{array}$ \\
\hline
\end{tabular}

- les plantes Nos $38,41,20,37$ de DO proche de celle des précédentes mais n'ayant pas fait l'objet du $1^{\text {er }}$ test (un seul résultat);

- toutes les autres plantes, de DO très supérieure à celle du témoin sain.

Le premier groupe semble débarrassé de la mosaïque. II représente $27 \%$ du matériel testé. La considération des 2 premiers groupes porterait le taux de succès à $39 \%$.

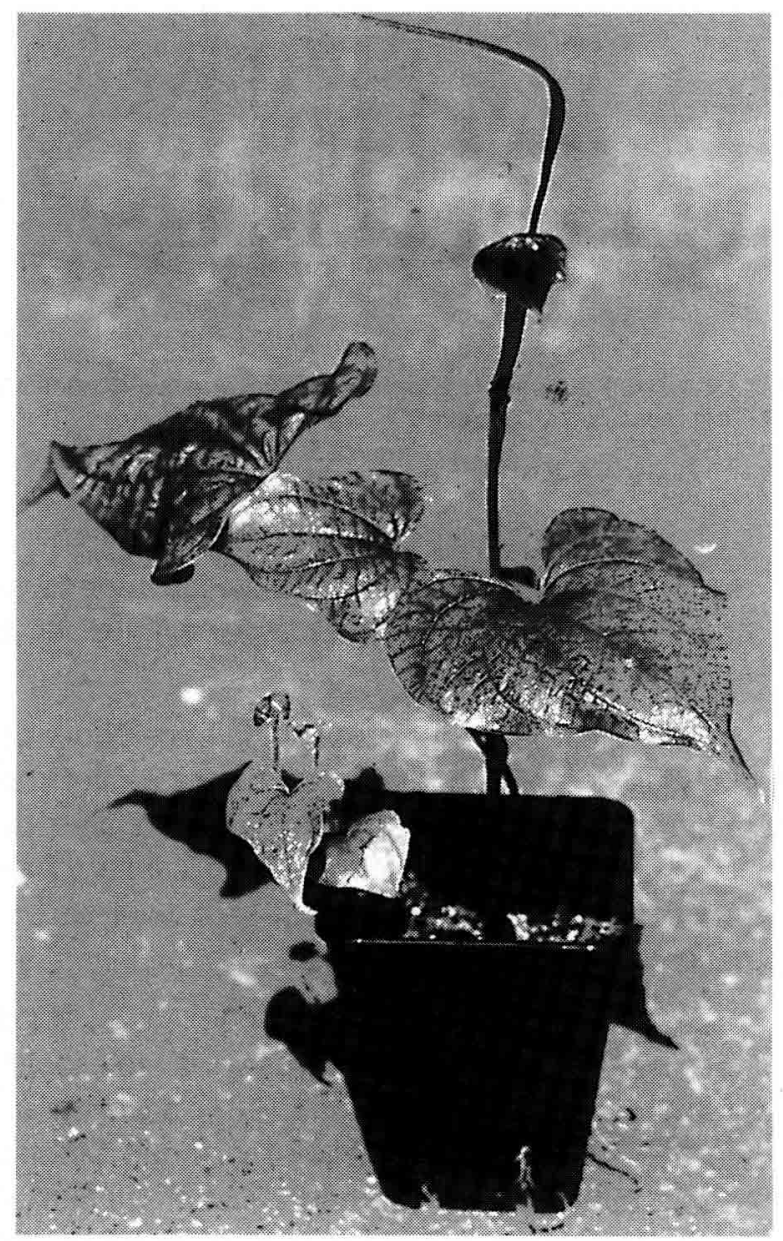

Fig 6. Plantule de $D$ trifida avec symptômes de mosaïque.

\section{DISCUSSION - CONCLUSION}

Plusieurs remarques peuvent être faites concernant le développement de méristèmes apicaux chez $D$ trifida, et sa portée dans l'élimination du virus de la mosaïque.

- La reprise de la croissance des apex, la phase la plus délicate car elle conditionne la réussite des étapes ultérieures, semble favorisée par l'emploi d'un milieu liquide mais les pertes restent encore trop importantes, de l'ordre de $29 \%$. La composition minérale du milieu joue un rôle non négligeable sur le développement et la multiplication des pousses. Les apex manifestent une meilleure reprise en présence de la solution N 30 K de Margara (1978) comme l'avait déjà remarqué l'un de nous (Degras, 1983) avec des boutures nodales. Cette supériorité sur le milieu de Murashige et Skoog (1962) conforte l'opinion de Margara (1978) selon laquelle la teneur en azote de ce dernier pourrait être excessive pour de nombreuses espèces. La teneur en azote doit être limitée dans toutes les phases de la croissance de $D$ trifida. Mais, la supériorité du milieu MS/2 à la phase d'accélération de la caulogenèse y établit l'avantage d'un abaissement du rapport $\mathrm{NO}_{3} / \mathrm{NH}_{4}$.

Cette variation dans la nature du milieu optimal avec l'évolution de la culture se retrouve pour la teneur en sucre, pour l'équilibre BAP/AIB et pour les teneurs respectives de ces hormones. Ainsi la croissance en phase initiale aurait peut-être pu bénéficier de teneurs en BAP supérieures à celles expérimentées, alors que la teneur est optimale à la phase suivante avec le dixième du maximum employé. On aura également remarqué, pour l'enracinement, la substitution de l'ANA à la BAP et à l'AIB, précédant la 

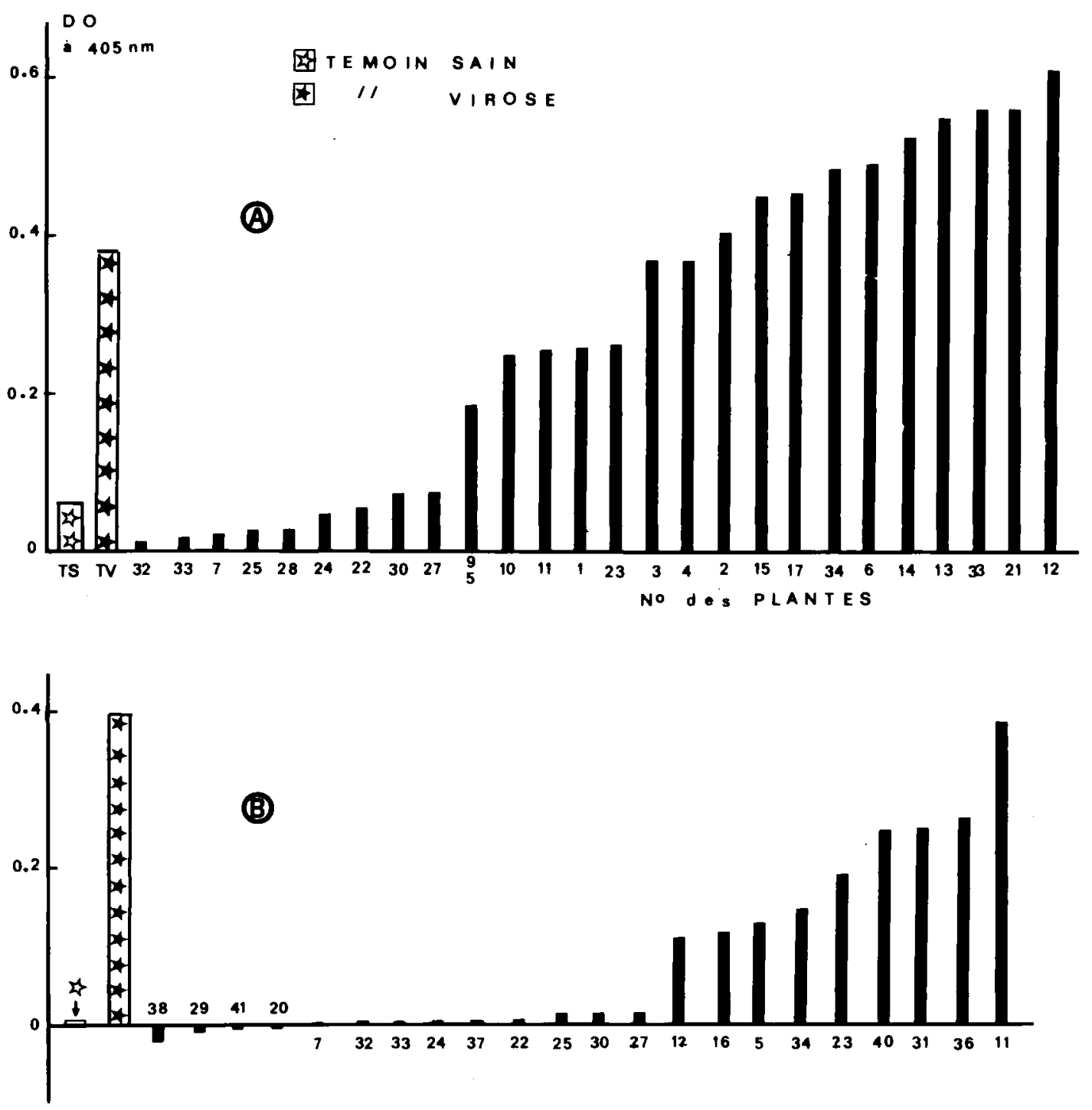

Fig 7. Détection du YMV par le test Elisa chez des plantes de $D$ trifida cv INRA 5-20 (sauf témoin sain : $D$ cayenensis-rotundata), $60 \mathrm{~min}$ après le dépôt du substrat. A. Test réalisé au mois de février; B. Test réalisé au mois d'avril.

suppression de toute hormone. On retrouve, en passant, la spécificité bien connue de l'ANA exploitée en horticulture (Margara, 1980) et confirmée en culture in vitro des Dioscorea par Chaturvedi (1975), Datta et al (1981), Cortes-Monllor et Liu (1983). Cette adaptation séquentielle de milieux à la croissance et à l'organogenèse in vitro correspond à la démarche de plusieurs auteurs chez d'autres plantes et pour divers objectifs, tels Boxus (1974) pour la propagation accélérée de fraisiers sains, ou Margara (1982) pour la néoformation de méristèmes. Chez l'igname, si elle est pratiquée par la plupart des chercheurs pour la néoformation (callogenèse puis organogenèse), elle demeure rare en micropropagation nodale et n'est pas signalée dans les cultures d'apex réussies. Ne serait-ce pas l'une des raisons du taux très modeste de régénération $19 \%$ déclaré chez $D$ alata par Mantell et al (1980) ?

- La détection du virus de la mosaïque de l'igname chez $D$ trifida en provenance de la Guadeloupe, avec l'antisérum d'origine africaine de Thouvenel et Fauquet, confirme le résultat obtenu par Edwige (Marchoux, 1980) sur diverses espèces des cultures antillaises.

Le taux d'élimination paraît peu élevé, dans nos essais, en comparaison des résultats obtenus chez le manioc (Kartha, 1981) ou le bananier (Surga-Rivas, 1983). II est vrai que Mantell et al (1980) n'avaient obtenu aucune élimination chez $D$ alata sans recourir à la thermothérapie de la plante mère. Une amélioration de nos ré- 
sultats pourrait donc être envisagée en associant la thermothérapie à l'isolement in vitro des apex.

En conclusion, la mise en œuvre des techniques de culture in vitro nous a permis d'obtenir des plantes débarrassées du virus de la mosaïque de l'igname par isolement des apex de $D$ trifida (Saleil, 1986). Cette méthode s'ajoute à celle mise en œuvre chez la même espèce par Balagne (1985). Cet auteur a appliqué au clone INRA 5-20 une thermotherapie, de $42^{\circ} \mathrm{C}$ sur $22 \mathrm{j}$ de croissance de vitroplantules initialement âgées de $20 \mathrm{j}$. La micropropagation nodale des portions développées pendant le traitement, chez les plantes moyennement virosées, conduit à des régénérations saines. Le nombre d'individus traités dans les 2 cas étant malgré tout limité, il n'est pas possible d'évaluer comparativement les 2 méthodes. On peut supposer que tout comme la micropropagation nodale (Arnolin, 1985), l'efficacité de chacune pourra varier avec le clone. Mais on doit noter que comparativement aux résultats de Mantell et Haque (1979) la régénération à partir de méristème apical de $D$ trifida est obtenue bien plus rapidement que celle de $D$ alata (6 mois après prélèvement de l'apex). A notre connaissance, $D$ trifida n'avait pas encore bénéfi- cié de l'application complète de la culture d'apex à sa sélection sanitaire, les obtentions récentes de clones de cette espèce à partir d'apex, signalées par Salazar et Fernandez (1985), n'ayant pas été testées pour l'élimination de virus.

Les résultats obtenus permettent de proposer le schéma de la figure 8 pour la culture in vitro de $D$ trifida en vue de l'élimination du YMV.

Certes, les conditions de la recontamination et de sa vitesse, en particulier, doivent être étudiées pour une application à la production commerciale de $D$ trifida où l'on peut craindre (Marchoux, 1980, Balagne, 1985) des recontaminations rapides en saison de plantation usuelle. Les résultats présentés n'en constituent pas moins une nouvelle avancée dans les possibilités de modernisation de la culture de l'igname, y compris les échanges génétiques.

\section{REMERCIEMENTS}

Les auteurs remercient vivement $P$ Dublin, qui en tant que directeur du laboratoire de culture des tissus du CIRAD a contribué à l'élaboration de cette recherche.

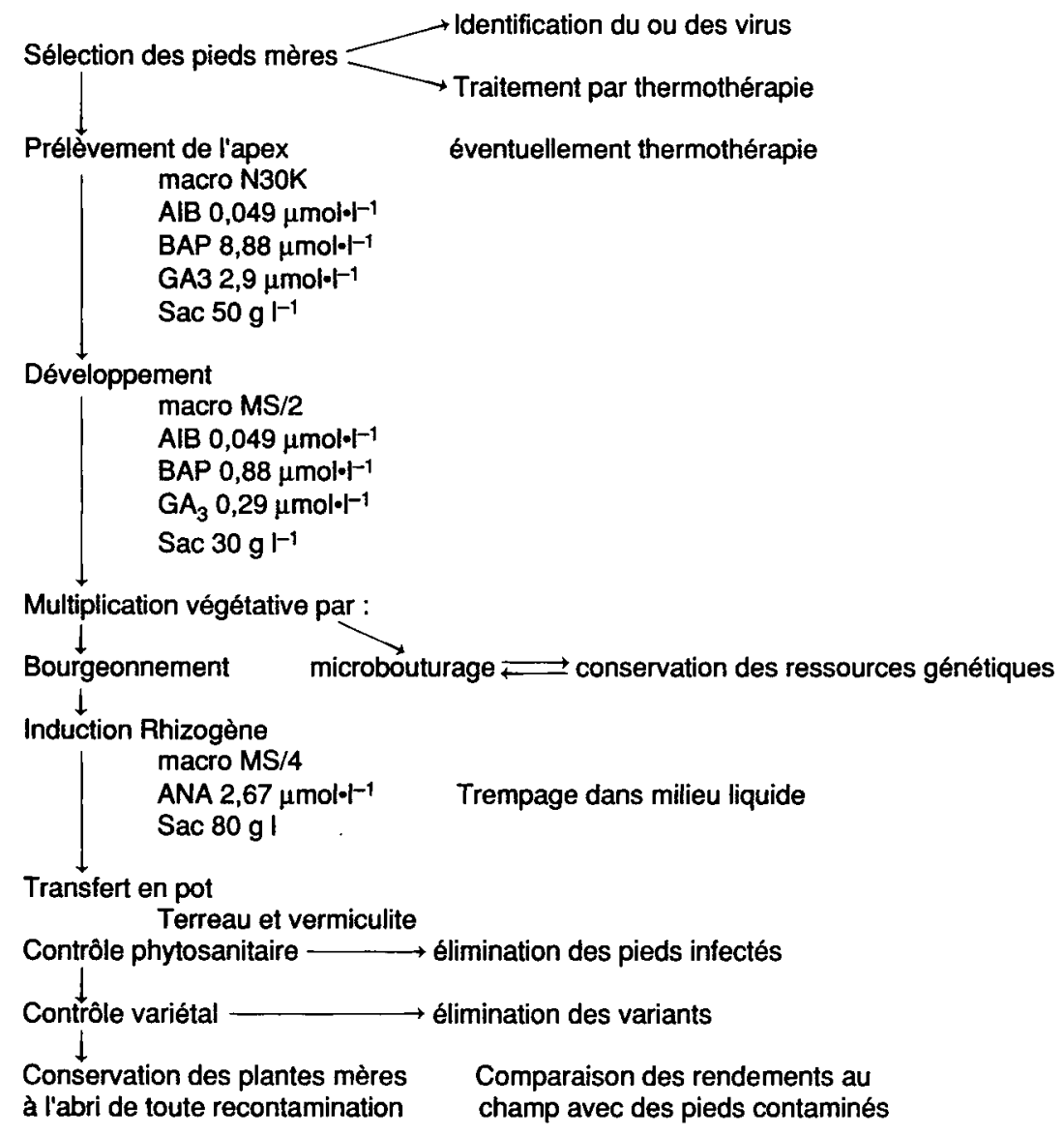

Fig 8. Schéma de production de plantes saines par les cultures d'apex chez l'igname Dioscorea trifida L. 
JC Thouvenel, virologue du centre ORSTOM de Côted'Ivoire pour la fourniture de l'antisérum utilisé et JB Quiot (INRA) du laboratoire de phytovirologie des pays chauds (CIRAD) qui a très aimablement permis l'étude immuno-enzymatique et a bien voulu faire bénéficier notre rédaction de judicieuses observations. $F$ Dosba et G Marchoux ont, par leurs critiques constructives, permis une rédaction et une réflexion plus rigoureuses. Nous les assurons de notre gratitude.

\section{RÉFÉRENCES}

Adsuar J (1955) A mosaic disease of the yam Dioscorea rotundata in Puerto Rico. J Agric Univ PR 39, 11-144

Arnolin R (1980) Culture in vitro et amélioration de l'igname (Dioscorea L). In : L'igname, Séminaire int, Guadeloupe, les colloques de l'INRA, 1981, 255268

Arnolin R (1985) Bouturage in vitro et production de plants chez l'Igname (Dioscorea spp). Thèse de IIIe cycle. Université Paris-Sud-Orsay. $140 \mathrm{p}$

Arnolin R, Degras L (1983) In vitro culture: results and prospects for food yams. V/e Symp ISTRC, Lima, Pérou, 21-26 février 1983, CIP, 641-648

Balagne M (1985) Le microbouturage in vitro de l'igname cousse-couche, Dioscorea trifida en vue de son application pour la guérison de variétés atteintes de viroses. Thèse de $3^{e}$ cycle en Sci agron, option Biol appl l'agric, USTL, Montpellier, $144 \mathrm{p}$

Boxus P (1974) The production of strawberry plants by in vitro micropropagation. J Hort Sci 49, 209-210

Chaturvedi MC (1975) Propagation of Dioscorea floribunda from in vitro culture of single-node stem segments. Curr Sci (Bangalore) 4423, 839-841

Clark MF, Adams AN (1977) Characteristics of the microplate method of enzyme linked immunosorbent assay for the detection of plant viruses. J Gen Virol $34,475-483$

Cortes-Monllor A, Liu LJ (1983) Tissue culture propagation of yam in Puerto-Rico. J Agric Univ P R 65, 419-420

Coursey DG (1967) Yams. Longmans, London, 230 p

Datta SK, Datta K, Datta PC (1981) Propagation of yam Dioscorea composita through tissue culture. In: Tissue culture of economically important plants. Proc of the Inter Symp held at the National Univ of Singapore, 28-30 avril 1981, (Rao AN ed) 90-93

Degras $L$ (1978) Les problèmes d'amélioration génétique de l'igname vus à travers ceux de Dioscorea trifida L. In: Yams (Miege J, Lyonga SN, eds) Inter Seminar on Yams. Buea Cameroun. Clarendon Press, Oxford, 1982, 3-16

Degras $L$ (1983) Different behaviours of cultivars of $D$ alata and $D$ trifida cultivated in vitro. Proc of Caribbean Regional Workshop on tropical Root Crops. David Dolly, Jamaique, 209-214

Degras L (1986) L'igname. Tech agric et prod trop, Maisonneuve et Larose, Paris, $409 p$
Degras L, Arnolin R, Poitout R (1980) Les principaux défauts de l'igname cousse-couche $D$ trifida et les recherches pour leur correction génétique. In : L'igname, Séminaire int Guadeloupe, les colloques de I'INRA, 1981, 221-228

Fauquet C, Thouvenel JC (1987) Maladies virales des plantes en Côte-d'Ivoire. Orstom, 243 p

Gautheret R (1959) La culture des tissus végétaux. Masson, Paris. 863 p

Grewal S, Koul S, Sachdeva V, Atal CK (1977) Regeneration of plants of Dioscorea deltoidea Wall by apical meristem cultures. Indian J Expl Biol 15, 201 203

Harrisson BD, Roberts IM (1973) Association of viruslike particles with internal brown spot of yams (Dioscorea alata). Trop Agric 50, 335-340

Kartha KK (1981) Meristem culture and cryopreservation. Methods and applications. In: Plant tissue culture. (Thorpe TA, ed) 181-211

Mantell SH, Haque SQ (1979) Disease-free yams: their production, maintenance and performances. Caribbean Agric Res Dev Inst Trinidad, Yam Virus Bull 2, 22 p

Mantell SH, Haque SQ, Phelps RH (1977) Virus diseases of yams in the Commonwealth Caribbean, ODM Yam virus project. Technical Report

Mantell SH, Haque SQ, Phelps RH (1978) Clonal multiplication of Dioscorea alata $\mathrm{L}$ and Dioscorera rotundata Poir yams by tissue culture : $J$ Hortic Sci 53, 95-98

Mantell SH, Haque SQ, Whitehall AP (1980) Apical meristem tip culture for eradication of flexous rod viruses in yams (Dioscorea alata). Trop Pest Manage 2627

Marchoux G (1980) Pathologie des ignames en Guadeloupe. Maladies virales. In : L'igname. Séminaire international, Guadeloupe. Les colloques de l'INRA, 1981, 93-100

Marchoux G, Edwige S, Migliori A (1979) Sur quelques propriétés biologiques du virus de la mosaïque de l'lgname Dioscorea spp, isolé en Guadeloupe. Ann Phytopathol 11, 535-538

Margara J (1978) Mise au point d'une gamme de milieux minéraux pour les conditions de la culture in vitro. CR Acad Agric Fr 8, 651-661

Margara J (1980) La culture de méristème et d'apex de tige. In : La multiplication végétative des végétaux supérieurs. (Chaussat R, Bigot $\mathrm{C}$, eds) Gauthier-Villars, 115-131

Margara J (1982) Bases de la multiplication végétative. Les méristèmes et l'organogenèse. INRA, $262 p$

Migliori A, Cadilhac B (1976) Contribution à l'étude de la maladie à virus de l'igname Dioscorea trifida en Guadeloupe. Ann Phytopathol 8, 73-78

Mohamed N, Mantell SH (1976) Incidence of virus symptoms in yam (Dioscorea $s p$ ) foliage in the Commonwealth Caribbean. Trop Agric 53, 255-261 
Murashige T, Skoog $F$ (1962) A revised medium for rapid growth and bioassays with tobacco tissue cultures. Physiol Plant 15, 437-494

NG SYC (1988) Tissue culture of cassava and yams at IITA. In : Use of biotechnology for the improvement of Cassava, Yams and Plantain in Africa. IITA Meeting Reports Series 1988/2, 49-50

Reckhaus P, Nienhaus F (1981) Etiology of a virus disease of white yam (Dioscorea rotundata) in Togo. $J$ Plant Dis Prot 88, 492-509

Salazar S, Fernandez ZZ (1985) Thermotherapy, shoot tip culture, axillary bud proliferation and plant regeneration in yam. (Dioscorea trifida L). VIIth Symp Int Soc Trop Root Crops. Gosier (Guadeloupe) 1-6 July 1985, INRA, 1988, 439-445

Saleil V (1986) Développement in vitro des apex isolés à partir de deux espèces d'igname : Dioscorea alata et Dioscorea trifida. Thèse de $3^{e}$ cycle, Sciences agron, option Phytotech, USTL, Montpellier, $149 \mathrm{p}$

Sawada E, Yakuwa T, Imakawa S (1958) Studies on the formation of aerial tubers in Chinese yam. II. On the aerial tuber formation in sterile culture of vine segments. J Hortic Assoc 27, 241-244

Sengupta J, Mitra GC, Sharma AK (1984) Organogenesis and tuberization in cultures of Dioscorea floribunda. Plant Cell Tissue Organ Cult 3, 325-331

Surga-Rivas JG (1983) Obtention de plantes indemnes de certaines infections parasitaires par culture d'apex isolés in vitro chez deux cultivars de ba- nanier : «Poyo" et «Giant Cavendish" (Musa, groupe AAA, sous-groupe Cavendish). Thèse de Docteur-Ingénieur, USTL, Montpellier. $148 \mathrm{p}$

Terry ER (1978) A Dioscorea rotundata virus disease in Nigeria. In : Yams. Int Seminar on Yams. Buea Cameroun. (Miege J, Lyonga SN, eds) Clarendon Press, Oxford, 1982, 239-244

Thouvenel JC, Fauquet C (1977) Une mosaïque de l'igname (Dioscorea cayenensis) causée par un virus filamenteux en Côte-d'lvoire. CR Acad Sci Paris CCLXXXIV, 1947-1949

Thouvenel JC, Fauquet C (1979) Yam mosaic, a new potyvirus infecting Dioscorea cayenensis in the Ivory Coast. Ann Appl Biol 93, 279-283

Thouvenel JC, Fauquet C (1980 a) Problèmes virologiques de l'igname en Côte-d'lvoire. In : I'lgname. Séminaire international, Guadeloupe. Les colloques de I'INRA, 1981, 101-105

Thouvenel JC, Fauquet C (1980 b) Utilisation de la technique ELISA dans le diagnostic de la mosaïque de l'Igname. $2^{e}$ Conf int sur l'impact des maladies à virus sur le développement des Pays Africains et du Moyen-Orient. Nairobi 2-6 déc 1980

Thouvenel JC, Fauquet C (1986) Yam Mosaic Virus, Description of Plant Viruses, No 314 , Assoc Appl Biol Kew, Surrey, England

Uduebo AE (1971) Effect of external supply of growth substances on axillary proliferation and development in Dioscorea bulbifera. Ann Bot 36, 159-163 